\title{
EDITORIAL
}

\section{New methods in brain imaging 1}

\section{X-RAY COMPUTED TOMOGRAPHY}

In the course of the last decade X-ray computed tomography has become firmly established in the neuroradiological diagnostic armamentarium, and the value of this procedure for neurological and neurosurgical practice hardly needs to be emphasized. By measuring the degree to which a beam of $\mathrm{X}$-rays is attenuated along its path through the tissues, the technique produces high-resolution pictures of brain morphology and readily detects most structural pathological changes of clinical relevance. The facility of its use suffers only minor shortcomings from the patient's exposure to ionizing radiation and the risk of adverse effects from the administration of contrast medium. It is easily repeatable and allows the monitoring of the effects of diseases and therapeutic interventions on cerebral structural integrity.

In psychiatry, the practical contribution of X-ray CT-scanning lies in the exclusion of treatable structural brain disease. Research has centred on the quantification of cerebral atrophy and, to a lesser degree, on measurements of brain-tissue density and the relative sizes of anatomical structures. Abnormalities have been reported in a range of psychiatric disorders, and it appears that their presence or absence can, in some instances, be helpful in the subclassification of disease entities (Reveley, 1985) or even in diagnosis (Naeser et al. 1980; Albert et al. 1984). However, such findings are non-specific and their pathogenesis remains unknown.

Two new medical imaging procedures have been developed: nuclear magnetic resonance (NMR) and positron emission tomography (PET). They rest on quite different technical principles but both have the potential of providing a wealth of physiological and biochemical information.

\section{NUCLEAR MAGNETIC RESONANCE}

NMR is a spectroscopic technique which makes use of the magnetic moments exhibited by some atomic nuclei to identify their distribution in the body. Suitable nuclei among the components of living matter are hydrogen (the proton, ${ }^{1} \mathrm{H}$ ), carbon $\left({ }^{13} \mathrm{C}\right)$, sodium $\left({ }^{23} \mathrm{Na}\right)$ and phosphorus $\left({ }^{31} \mathrm{P}\right)$. At present, NMR imaging rests almost entirely on the spatial delineation of protons and some of their associated NMR parameters such as relaxation times, which provide information about their interaction with their chemical environment. Proton imaging is highly sensitive to fat and water content. Compared with X-ray CT-scanning the contrast between grey and white matter is greatly enhanced. For the investigation of posterior fossa pathology and cerebral atrophy NMR has the additional advantage that the pictures are free of bone artefacts. The sensitivity of NMR imaging for the investigation of brain morphology has been demonstrated most impressively in the enhanced detection of cerebral lesions in patients with multiple sclerosis (Young et al. 1981). However, changes often lack specificity - for example, tumour, infarction and oedema may be indistinguishable from each other. Some of these problems may be overcome in the future by the use of paramagnetic contrast agents and more experience in image production and interpretation.

Numerical analysis of proton NMR parameters has been performed in patients with Alzheimer's dementia and multi-infarct dementia, and seems to be able to distinguish the two groups of patients from each other and from normal controls (Besson et al. 1985). In chronic alcoholics, changes suggestive of decreased brain water content during intoxication and increased water content during

1 Address for correspondence: Dr S. Herold, The Maudsley Hospital, Denmark Hill, London SE5 8AZ. 
withdrawal have been demonstrated (Besson et al. 1981). However, as only few neurological and psychiatric conditions have been investigated in a systematic way to date, it is not yet clear how specific these abnormalities are and, like the density changes seen on X-ray CT-scans, what they mean in biochemical terms.

Nuclei other than protons are difficult to image as their signals are present in much smaller quantities than hydrogen and are less sensitively detected by the NMR technique. Pictures of cerebral sodium distribution have been obtained, and increased sodium concentrations in cerebral infarcts, tumours and oedema have been reported (Hilal et al. 1985). Phosphorus-NMR is inadequate for imaging purposes and there are theoretical reasons to believe that this will never be possible in man. However, local spectra can be obtained which provide information about tissue $\mathrm{pH}$ and the relative concentrations of phosphorus metabolites - for example, ATP and ADP and phosphocreatinine. NMR spectroscopy requires technological modifications of the imaging apparatus and procedures. In humans in vivo ${ }^{31} \mathrm{P}$-studies to date have mainly been performed in forearm muscle (Radda $\mathrm{et}$ al. 1984) and in the brains of newborn infants (Hope et al. 1984). ${ }^{13} \mathrm{C}$-spectroscopy deals with even weaker signals and ${ }^{1} \mathrm{H}$-spectroscopy of, for example, amino acids has to be resolved in the presence of a huge water signal which has to be suppressed before such compounds can be examined. These analytical methods are still in an animal experimental stage. In essence, NMR has so far proved an extremely sensitive imaging technique, if somewhat lacking in differential discriminatory capacity but, contrary to the original expectations, little biochemical information about the human brain has emerged to date.

\section{POSITRON EMISSION TOMOGRAPHY}

Positron emission tomography (PET), though it too produces images of cerebral structures, has never been considered a tool for morphological studies. By systemically administering as tracers compounds labelled with short-lived positron-emitting isotopes and tomographically recording their distribution within the body, PET enables classical quantitative tracer techniques to be extended to man in vivo. Commonly used radioactive labels are isotopes of biological elements: oxygen-15 $\left({ }^{15} \mathrm{O}\right.$, half-life $\left.2 \cdot 1 \mathrm{~min}\right)$, nitrogen-13 $\left({ }^{13} \mathrm{~N}\right.$, half-life $\left.10 \mathrm{~min}\right)$, carbon-11 $\left({ }^{11} \mathrm{C}\right.$, half-life $\left.20 \cdot 1 \mathrm{~min}\right)$. Fluorine-18 $\left({ }^{18} \mathrm{~F}\right.$, half-life $\left.110 \mathrm{~min}\right)$ can be substituted for hydrogen for which no positron emitting isotope exists. These isotopes can be used to label a wide variety of biochemical and pharmacological compounds without altering their biological behaviour or biochemical fate. If appropriate tracer models are available to describe the fate of the labelled compounds in the human body, parameters of tissue function can be measured regionally and quantitatively.

To date, the PET procedures furthest developed and best understood are those for measuring regional cerebral blood flow, blood volume and energy metabolism. ${ }^{15} \mathrm{O}$-labelled molecular oxygen can be used to measure the cerebral metabolic rate of oxygen, ${ }^{18} \mathrm{~F}$-labelled deoxyglucose or ${ }^{11} \mathrm{C}$-labelled glucose for measurements of the metabolic rate of glucose. These techniques have been applied to a wide range of neurological conditions. Metabolic rates for glucose in gliomas have been found to correlate with the histological grade (Di Chiro et al. 1981). In Huntington's chorea caudate glucose metabolism has been shown to be significantly depressed in early disease (Kuhl et al. 1982). The most interesting observations, however, have emerged from the ability to perform combined measurements of several physiological parameters in the same subject and to study the interrelationships - the relation between flow and metabolic rates reflecting the balance between substrate supply and consumption, the ratio of blood flow to blood volume providing information about cerebral haemodynamics. These multiple tracer studies have yielded new pathophysiological information, in particular in cerebrovascular disease (Powers \& Raichle, 1985) and in tumours (Beaney, 1984), conditions where uncoupling between supply and demand has been a frequent finding.

The psychiatric disorders most extensively studied to date are dementia and schizophrenia. Both in Alzheimer's and multi-infarct dementia, decreased metabolic rates for oxygen and glucose have been found consistently (Frackowiak et al. 1981; Benson et al. 1983). The overall reduction in cerebral oxygen consumption (and blood flow) correlates with the clinical severity of the disease 
and not the type of dementia, but focal patterns of metabolic impairment seem to discriminate between the two groups. An important finding has been that the general and focal decline in flow and oxygen metabolism is strictly coupled. No mismatching which would give evidence of a state of chronic ischaemia and serve as a rationale for the use of vasodilator drugs in these conditions has been observed.

As might perhaps be expected, the findings in schizophrenia are less clear cut. Studies on about a hundred patients have been communicated to date in the open literature investigating either blood flow and oxygen metabolism (Sheppard et al. 1983) or glucose metabolism (Widen et al. 1981, 1983; Buchsbaum et al. 1982, 1984; Farkas et al. 1984; Brodie et al. 1984; Clark et al. 1984; De Lisi et al. 1985; Wiesel et al. 1985). Preliminary results have been reported from the investigation of local protein synthesis with ${ }^{11} \mathrm{C}$-L-methionine (Bustany et al. 1985). Since Ingvar \& Franzen (1974), using the intraarterial ${ }^{133}$ Xenon injection technique, demonstrated normal mean hemispheric flow but relatively decreased flow in frontal regions in schizophrenic patients when compared with a control group of neurologically and psychometrically normal chronic alcoholics, all metabolic studies have been performed with this concept of 'hypofrontality' in mind. Other issues of interest have been the question of hemispheric laterality and basal ganglia dysfunction. The patient populations studied with PET have varied in terms of diagnostic criteria, duration of illness, treatment and sensory stimulation during the scanning procedures. Hence the reported results have to be considered in the light of these variations. None of the studies that has addressed this question has found differences in the metabolic rates of whole brain or whole cortex between schizophrenics and normal volunteers. 'Hypofrontality', usually assessed as frontal: whole plane or frontal:posterior ratio, has not been seen in patients with short duration of the disease, whether on neuroleptics or not. 'Hypofrontality' seems to be related to chronic illness in which relatively lower frontal metabolic rates have been consistently reported. These have been mostly bilaterally, though in one study only on the left side (Brodie et al. 1984). Several investigators performed double studies before and after varying periods of neuroleptic treatment. Treatment tended to increase cerebral metabolic rates for glucose slightly but 'hypofrontality', when present, was found to persist. Buchsbaum et al. (1984) extended their investigations to 11 patients with affective disorders (10 bipolar, 1 unipolar, all in the depressed phase), in whom they found hypofrontality to the same degree as in the schizophrenic group. This raises the question of the specificity of the variable.

The only other study which examined glucose metabolism in affective psychosis (Baxter et al. 1985) found no difference in whole brain glucose consumption between unipolar depressed patients, patients with bipolar depression in the manic phase and normal subjects. Patients with bipolar depression in the depressed phase or in a mixed state with psychomotor activity and depressed mood had significantly lower rates. 'Hypofrontality' was not observed. Bipolar depressed patients who were rescanned in either euthymia or hypomania showed a higher metabolic rate in the more elevated mood. These interesting findings which were made in a small number of patients and showed considerable overlap between the groups need confirmation by a larger study.

Increased cerebral metabolic rates of glucose were reported in young autistic men (Rumsey et al. 1985), but this was not confirmed in a subsequent study which found normal values for blood flow, oxygen metabolism and glucose metabolism in autism (Herold et al. 1985a).

It seems appropriate to question whether in psychiatric disorders the study of cerebral energy metabolism should be pursued, since its impairment is after all a non-specific feature of neuronal failure. In those diseases in which changes are dramatic and progressive, as in the dementias, entities of regional tissue metabolism should be helpful in the objective evaluation of the efficacy of therapeutic regimes. Otherwise, investigations which address the pathogenetic mechanism more directly - for example, the study of neurotransmitter pathways - seem more promising. Techniques have been developed which allow the study of the pre- and postsynaptic dopaminergic system (Garnett et al. 1983; Wagner et al. 1983; Leenders et al. 1984; Farde et al. 1985, 1986), opiate receptors (Frost et al. 1985; Jones et al. 1985) and benzodiazepine receptors (Comar et al. 1979). A wide range of pharmaceuticals is, in principle, amenable to labelling with positron emitters. Most of these new techniques have just reached a stage at which they are applicable to humans. 
Methylspiperone labelled with ${ }^{11} \mathrm{C}$ has been used to study dopamine (and serotonin) receptor affinity in a small group of untreated schizophrenic patients and a larger group of patients with Parkinson's disease (Herold et al. 1985 b; Leenders et al. 1985). No differences in striatal methylspiperone uptake compared with normal subjects were found, but this could be due to methodological problems in that the ${ }^{11} \mathrm{C}$-label might be too short-lived to study specific uptake. Baron et al. (1985) found a striking reduction in striatal and frontal binding of spiperone labelled with bromine-76 (half-life 16.2 hours) in patients with progressive supranuclear palsy.

The application of PET to psychiatric disorders is in its infancy but has certainly opened up a wide field of research. The studies performed to date indicate the scope of this technique for the investigation of cerebral physiology, biochemistry and pharmacology. PET-facilities (which need a scanner as well as a cyclotron for the production of short-lived isotopes) will always be rare and expensive. To make best use of the potential, appropriate pathophysiological questions, clearly defined patient groups, valid tracer models and careful data analysis are required.

SIGRID HEROLD AND RICHARD J. FRACKOWIAK

\section{REFERENCES}

Albert, M., Naeser, M. A., Levine, H. L. \& Garvey, A. J. (1984). CT density numbers in patients with senile dementia of the Alzheimer type. Archives of Neurology 41, 1264-1269.

Baron, J. C., Maziere, B., Loch, C., Sgouropoulos, P., Bonnet, A. M. \& Agid, Y. (1985). Progressive supranuclear palsy: loss of stratal dopamine receptors demonstrated in vivo. Lancet $\mathrm{i}, 1163-1164$.

Baxter, L. R., Phelps, M. E., Mazziotta, J. C., Schwartz, J. M., Gerner, R. H., Selin, C. E. \& Sumida, R. M. (1985). Cerebral metabolic rates for glucose in mood disorders: studies with positron emission tomography and fluorodeoxyglucose F18. Archives of General Psychiatry 42, 441-447.

Beaney, R. P. (1984). Positron emission tomography in the study of human tumors. Seminars in Nuclear Medicine 14, 324-341.

Benson, D. F., Kuhl, D. E., Hawkins, R. A., Phelps, M. E., Cummings, J. L. \& Tsai, S. Y. (1983). The fluorodeoxyglucose ${ }^{8} \mathbf{F}$ scan in Alzheimer's disease and multi-infarct dementia. Archives of Neurology 40, 711-714.

Besson, J. A. O., Glen, A. I. M., Foreman, E. I., MacDonald, A. Smith, F. W., Hutchison, J. M. S., Mallard, J. R \& Ashcroft, G. W. (1981). Nuclear magnetic resonance observations in alcohohic cerebral disorder and the role of vasopressin. Lancet ii, 923-924.

Besson, J. A. O., Corrigan, F. M., Foreman, E. I., Eastwood, L. M., Smith, F. W. \& Asheroft, G. W. (1985). Nuclear magnetic resonance (NMR) II. Imaging in dementıa. British Journal of Psychiatry 146, 31-35.

Brodie, J. D., Christman, D. R., Corona, J. F., Fowler, J. S., Gomez-Mont, F., Jaeger, J., Micheels, P. A., Rotrosen, J., Russell, J. A., Volkow, N. D., Wikler, A., Wolf, A. P. \& Wolkıns, A. (1984) Patterns of metabolic activity in the treatment of schizophrenia. Annals of Neurology 15 (Suppl.), S166-S169.

Buchsbaum, M. S., Ingvar, D. H., Kessler, R., Waters, R. N., Cappelletti, J., van Kammen, D. P., King, A. C., Johnson, J. L., Manning, A. G., Plynn, R. W., Mann, L. S., Bunney, W. E. \& Sokoloff, L. (1982). Cerebral glucography with positron tomography. Archives of General Psychiatry 39, 251-259.

Buchsbaum, M. S., De Lisi, L. E., Holcomb, H. H., Cappelletti, J., King, A. L., Johnson, J., Hazlett, E., Dowling-Zimmerman, S., Post, R. M., Morhisa, J., Carpenter, W., Cohen, R., Pickar, D. Weinberger, D. R., Margolin, R. \& Kessler, R. H. (1984). Anteroposterior gradients in cerebral glucose use in schizophrenia and affective disorders. Archives of General Psychiatry 71, $1159-1166$

Bustany, P., Henry, J. F., De Roton, J., Signoret, P., Cabanis, E., Zarifian, E., Ziegler, M., Derlon, M., Crousel, C., Soussaline, F. \& Comar, D. (1985). Correlations between clinical state and positron emission tomography measurements of local brain protein synthesis, in Alzheimer's dementia, Parkinson's disease, schizophrenia, and gliomas. In The Metabolism of the Human Brain Studied with Positron Emission Tomography (ed. T. Greitz, D. H. Ingvar and L. Widen), pp. 241-249. Raven Press: New York.

Clark, C. M., Kessler, R., Buchsbaum, M. S., Margolin, R. A. \& Holcomb, H. H. (1984). Correlational methods for determining regional coupling of cerebral glucose metabolism: pilot study. Biological Psychiatry 19, 663-678.

Comar, D., Maziere, M., Gadot, J. M., Berger, G. \& Soussaline, F. (1979). Visualisation of ${ }^{11} \mathrm{C}$-flunitrazepam displacement in the brain of the live baboon. Nature 280, 329-331.

Di Chiro, G., De La Paz, K., Smith, B., Kornblith, P., Sokoloff, L., Brooks, R., Blasberg, C., Cummins, C., Kessler, R., Wolf, A., Fowler, J., London, W. \& Sever, J. (1981). ${ }^{18} \mathrm{~F}-2$-fluoro-2deoxyglucose positron emission tomography of human cerebral gliomas. Journal of Computer Assisted Tomography 5, 937-938.

De Lisi, L. E., Holcomb, H. H., Cohen, R. M., Picker, D., Carpenter, W., Morilisa, J. M., King, A. C., Kessler, R. \& Buchsbaum, M. S. (1985). Positron emission tomography in schizophrenic patients with and without neuroleptic medication. Journal of Cerebral Blood Flow and Metabolism 5, 201-206.

Farde, L., Ehrin, E., Eriksson, L., Greitz, T., Hall, H. \& Sedvall, G. (1985). 11-C-labelled dopamine-D2 receptor antagonists as tools for quantitative studies on dopamine receptors in the human brain. Journal of Cerebral Blood Flow and Metabolism 5 (Suppl. 1), S595-596.

Farde, L., Hall, H., Ehrin, E. \& Sedvall, G. (1986). Quantitative analysis of $\mathrm{D}_{2}$ dopamine receptor binding in the living human brain by PET. Science 231, 258-261.

Farkas, T., Wolf, A. P., Jaeger, J., Brodie, J., Christman, D. R. \& Fowler, J. S. (1984). Regional brain glucose metabolism in chronic schizophrenia. Archives of General Psychialry 41, 293-300.

Frackowiak, R. S. J., Pozzilli, C., Legg, N. J., DuBoulay, G. H. Marshall, J., Lenzi, G. L. \& Jones, T. (1981). Regional cerebral oxygen supply and utilisation in dementia: a clinical and physiological study with oxygen-15 and positron tomography. Brain 104, 753-778.

Frost, J. J., Wagner, H. N., Dannals, R. F., Ravert, H. T., Links, J. M., Wilson, A. A., Burns, H. D., Wong, D. F., McPherson, R. W., Rosenbaum, A. E., Kuhar, M. J. \& Snyder, S. H. (1985). Imaging opiate receptors in the human brain by positron tomography. Journal of Computer Assisted Tomography 9, 231-236.

Garnett, E. S., Firnau, G. \& Nahmias, C. (1983). Dopamine visualised in the basal ganglia of living man. Nature 305, 137-138. Herold, S., Frackowiak, R. S. J., Rutter, M. \& Howlin, P. (1985a). Regional cerebral blood flow, oxygen metabolism and glucose 
metabolism in young autistic adults. Journal of Cerebral Blood Flow and Metabolism 5 (Suppl. 1), S189-190.

Herold, S., Leenders, K. L., Turton, D. R., Kensett, J. M., Pike, V. W., Clark, J. C., Brooks, D. J., Crow, T. J., Owen, F., Cooper, S. \& Johnstone, E. C. (1985). Dopamine receptor binding in schizophrenic patients as measured with "C-methylspiperone and PET. Journal of Cerebral Blood Flow and Metabolism 5 (Suppl. 1), SI91-192.

Hilal, S. K., Maudsley, A. A., Ra, G. B., Simon, H. E., Roschmann, P., Wittekock, S., Cho, Z. H. \& Mum, S. K. (1985). In vivo NMR imaging of sodium-23 in the human head. Journal of Computer Assisted Tomography 9, 1-7.

Hope, P. L., Costello, A. M. del, Cady, E. B., Delpy, D. T., Tofts, P. S., Chu, A., Hamilton, P. A., Reynolds, E. O. R. \& Wilkie, D. R. (1984). Cerebral energy metabolism studied with phosphorus NMR spectroscopy in normal and birth-asphyxiated infants. Lancet ii, 366-370.

Ingvar, D. H. \& Franzen, G. (1974). Distribution of cerebral activity in schizophrenia. Lancel ii, 1484-1486.

Jones, A. K. P., Luthra, S. K., Pike, V. W., Herold, S. \& Brady, F. (1985). New labelled ligand for in-vivo studies of opioid physiology. Lancet ii, 665-666.

Kuhl, D. E., Phelps, M. E., Markham, C. H., Metter, E. J., Riege, W. H. \& Winter, J. (1982). Cerebral metabolism and atrophy in Huntington's disease determined by ${ }^{18} \mathrm{FDG}$ and computed tomographic scan. Annals of Neurology 12, 425-434.

Leenders, K. L., Herold, S., Brooks, D. J., Palmer, A. J., Turton, D., Firnau, G., Garnett, E. S., Nahmias, C. \& Veall, N. (1984). Presynaptic and postsynaptic dopaminergic system in human brain. Lancer ii, 110-111.

Leenders, K. L., Herold, S., Palmer, A. J., Turton, D., Quinn, N., Jones, T., Frackowiak, R. S. J. \& Marsden, C. D. (1985). Human cerebral dopamine system measured in vivo using PET. Journal of Cerebral Blood Flow and Metabolism 5 (Suppl. 1), \$157-158.

Naeser, M. A., Gebhardt, C. \& Levine, H. L. (1980). Decreased computerised tomography numbers in patients with presenile dementia: detection in patients with otherwise normal scans. Archives of Neurology 37, 401-409.

Powers, W. J. \& Raichle, M. E. (1985). Positron emission tomography and its application to the study of cerebrovascular disease in man. Stroke 16, 36I-376.

Radda, G. K., Bore, P. J. \& Rajagopalan, B. (1984). Clinical aspects of "P NMR spectroscopy. British Medical Bulletin 40, 155-159.

Reveley, M. A. (1985). CT scans in schizophrenia. British Journal of Psychiatry 146, 367-371.

Rumsey, J. M., Duara, R., Grady, C., Rapoport, J. L., Margolin, R. A., Rapoport, S. I. \& Cutler, N. R. (1985). Brain metabolism in autism. Archives of General Psychiatry 42, 448-455.

Sheppard, G., Gruzelier, J., Manchanda, R., Hirsch, S. R., Wise, R., Frackowiak, R. \& Jones, T. (1983). ${ }^{16} \mathrm{O}$ positron emission tomographic scanning in predominantly never-treated acute schizophrenic patients. Lancet ii, 1148-1152.

Wagner, H. N., Burns, D. H., Dannals, R. F., Wong, D. F., Langstrom, B., Duelfero, T., Frost, J. J., Ravert, H. T., Links, J. M., Rosenbloom, S. B., Lukas, S. E., Kramer, A. V. \& Kuhar, M. J. (1983). Imaging dopamine receptors in the brain by positron tomography. Sctence 22, 1264-1266.

Widen, L., Bergstrom, M., Blomqvist, G., Brimar, T., Ehrin, E., Elander, S., Eriksson, K., Eriksson, L., Greitz, T., Litton, J.-E., Malmborg, P., Wilsson, L., Sedvall, G. \& Ugglas, M. (1981). Glucose metabolism in patients with schizophrenia: emission computed tomography measurements with 11-C.Glucose. Journal of Cerebral Blood Flow and Metabolism 1 Suppl. 1, S455-S456.

Widen, L., Blomqvist, G., Greitz, T., Litton, J. E., Bergstrom, M., Ehrin, E., Ericson, K., Eriksson, L., Ingvar, D. H., Johansson, L., Nilsson, J. L. G., Stone-Elander, S., Sedvall, G., WieseJ, F. \& Wiik, G. (1983). PET studies of glucose metabolism in patients with schizophrenia. American Journal of Neuroradiology 4, 550-552.

Wiesel, F. A., Blomqvist, G., Ehrin, E., Greitz, T., Ingvar, D. H., Litten, J., Nilsson, L., Sedvall, G., Stone-Elander, S., Widen, L. \& Wiik, G. (1985). Brain energy metabolism in schizophrenia studied with ${ }^{11} \mathrm{C}$-glucose. In The Metabolism of the Human Brain Studied with Positron Emission Tomography (ed. T. Greitz, D. H. Ingvar and L. Widen), pp. 485-493. Raven Press: New York.

Young, I. R., Hall, A. S., Pallis, C. A., Bydder, G. M., Legg, N. J. \& Steiner, R. E. (1981). Nuclear magnetic resonance imaging of the brain in multiple sclerosis. Lancet ii, 1063-1066. 